\title{
Effect of Lymphatic Pump on Inflammatory Markers and Chest Expansion in Children with Community-Acquired Pneumonia \\ Manal Salah El Dein ${ }^{1}$, Saher Nour El Dein ${ }^{2}$, Asmaa Hassan*1 \\ ${ }^{1}$ Department of Physical Therapy for Growth and Development Disturbance in Children and its Surgery, Faculty of Medicine, Cairo, University, Egypt. \\ ${ }^{2}$ Department of Genetics, Faculty of Medicine, Ain Shams, University, Egypt \\ *Corresponding author: Asmaa Hassan, Mobile: (+20) 01157755155, E-Mail: mamasemsem99@yahoo.com
}

\begin{abstract}
Background: Community-acquired pneumonia (CAP) is the most common serious bacterial infectious disease in childhood. It is a leading cause of morbidity and mortality in children younger than the age of 5 years. Pneumonia is an invasion of the lower respiratory tract, that may result in an inflammation, injury or death of the surrounding epithelium and alveoli by a migration of inflammatory cells to the site of infection.

Objective: The purpose of this study was to detect the effect of Lymphatic pump as a physical therapy modality on controlling the inflammatory process and improving chest expansion in children complaining of CAP

Patients and methods: Thirty inpatient children with diagnosis of CAP ranging in age from 6 to 12 years were selected from El-Abbasia Chest Diseases Hospital. They were randomly assigned into two groups of equal number (control and study groups). Patients in both groups were treated by conventional chest physical therapy program while patients in the study group received an additional intermittent pneumatic compression, sessions were conducted three times per week till discharge. Inflammatory markers and chest expansion were measured before and after the suggested treatment period. Results: show a statistically significant improvement of c-reactive protein (CRP) and chest expansion while insignificant difference of WBCs count, absolute neutrophils, and lactate dehydrogenase (LDH) was recorded.

Conclusion: It could be concluded that intermittent Pneumatic compression is an effective physical therapy modality in treating children with community acquired pneumonia.
\end{abstract}

Keywords: Community acquired pneumonia, Inflammatory markers, chest physiotherapy, Intermittent Pneumatic compression.

\section{INTRODUCTION}

Pneumonia is an inflammatory condition of the lung affecting primarily the microscopic air sacs (alveoli) ${ }^{(\mathbf{1})}$. It is usually caused by infection with viruses or bacteria and less commonly other microorganisms and autoimmune diseases ${ }^{(2)}$. Pneumonia is a common illness affecting approximately 450 million people per year and occurring in all parts of the world. It is a major cause of death among all age groups resulting in 4 million deaths (7\% of the world's total death) yearly ${ }^{(3)}$.

The presentation of pneumonia includes fever, cough and pleuritic chest pain. Focal chest signs in child with pneumonia includes: decreased chest expansion, dullness on percussion, decreased entry of air, bronchial breathing, and crackles ${ }^{(4)}$. WBCs and CRP are a good diagnostic markers. WBCs are elevated in a direct proportional manner with severity of pneumonia as during infection, pro-inflammatory cytokines, chemokines are released from injured tissue to enter blood and lymph. Leukocytes utilize this inflammatory tissue gradient to detect sites of infection and inflammation in the body and directly kill pathogens and continue to release inflammatory mediators ${ }^{(5,6)}$.

Conventional physical therapy modalities that may be used to treat chest problems may include modified postural drainage that allows gravity to drain secretions from specific segments of the lungs. Shaking, percussion and vibration that may mobilize secretions. Coughing and huffing techniques that may be used to expectorate secretions and breathing exercises like diaphragmatic breathing that may be done to increase air entry, chest expansion, and to loosen secretions ${ }^{(7)}$.

Lymphatic pump technique (LPT) enhances the flow of lymph fluid through the lymphatic system ${ }^{(8)}$. It is used to treat infection and oedema and might be an effective adjuvant therapy in patients with pneumonia. LPT enhances the uptake of lymph into the lymphatic system and increases lymph flow and leukocyte output, LPT may enhance innate immunity ${ }^{(9)}$, which collects fluid, immune cells, antigens, pathogens and proteins from the tissue interstitial space and delivers them to regional lymph nodes ${ }^{(\mathbf{1 0})}$.

Intermittent pneumatic compression (IPC) is a form of Lymphatic pump therapeutic technique that force fluids such as blood and lymph, out of the pressurized area. After a short time the pressure is reduced, allowing increased blood flow back into the $\operatorname{limb}^{(\mathbf{1 1 1}}$. IPC has been proved to be successful, easy and inexpensive method ${ }^{(12)}$.

The aim of the current work was to detect the effect of Lymphatic pump as a physical therapy modality on controlling the inflammatory process and improving chest expansion in children complaining of CAP.

\section{PATIENTS AND METHODS}

This randomized controlled study (RCT) included a total of 34 children of both sexes suffering from pneumonia with age ranged from 6 to 12 years, attending at El Abbasia Chest Disease Hospital. This study was conducted between December 3, 2019, to December 12, 
2020. One patient withdrew from the study shortly after enrolling and two were dropped after completing the protocol without finishing the final investigation. Another patient withdrew from the study because of misdiagnosis after 2 sessions. The remaining thirty children who completed the study protocol were randomly assigned into 2 groups of equal number 15 patients in each, representing control and study groups respectively. Each child in both groups was evaluated before and after the suggested treatment duration to detect: the inflammatory markers (C-reactive protein, Lactate dehydrogenase, total white blood cell count, and absolute neutrophils) and chest expansion.

Patients in both groups were treated for 30 minutes session duration at a frequency of 3 sessions per week till discharge from the hospital.

\section{Treatment procedures:}

Patients in the Control group were treated by conventional chest physiotherapy (CCPT) in a form of postural drainage (that was applied after the child was placed in the appropriate position according to the affected lobe needed to be drained) using tilting table for $10 \mathrm{~min}$, percussion was applied for $3 \mathrm{~min}$ and vibration/ shaking were applied for 3 min (after postural drainage and from the same position).

Diaphragmatic breathing exercise was done from supine position for 5 times sets that was repeated for 10 min and resting for 30 seconds was given after each set. Teaching coughing and huffing technique was applied while child in sitting position for 4 min. Patients in the study group received the same CCPT program in addition to Lymphatic pump that was applied for $15 \mathrm{~min}$. It was applied by Intermittent Pneumatic compression apparatus (model: WHF-324 POWER-Q1000 PLUS,) which consists of air pump, an inflatable axillary sleeves and boots and pressure lines which are connected to the air pump (Figure 1). The pressure was applied on child chest and lower limb simultaneously. Duration of treatment in lower limb was 10 minutes, with pressure of 40-80 mm Hg. while for the chest it was applied for 15 minutes at Pressure of:30-60 mm Hg.

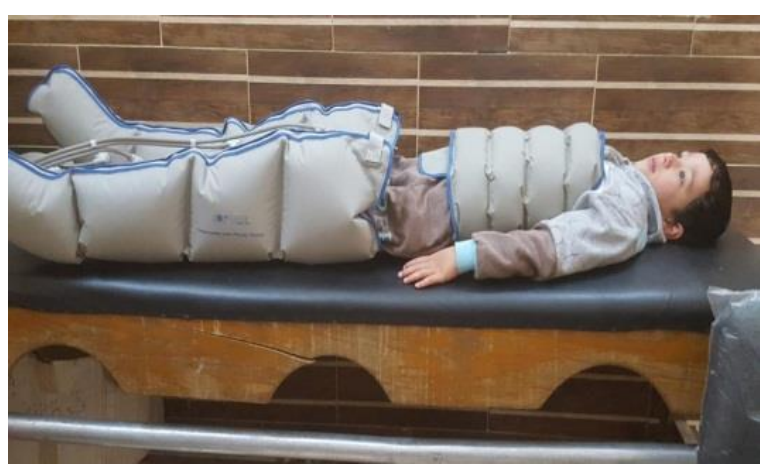

Fig. (1): Intermittent Pneumatic compression device.

\section{Ethical Consideration:}

An approval of the study was obtained from Cairo University academic and ethical committee. Every patient signed an informed written consent for acceptance of the operation. This work has been carried out in accordance with The Code of Ethics of the World Medical Association (Declaration of Helsinki) for studies involving humans.

In addition, approval of Ethical Committee, Faculty of Physical Therapy Cairo University was obtained with number of 012/002586. Parents or caregivers of the participants were asked to sign a consent form for their acceptance to participate in this study after explaining the aim and the procedures of the study.

\section{Statistical analysis}

Statistical Package for Social Sciences (SPSS) computer program (version 23 windows) was used for data analysis. Power analysis for a One-Way ANOVA Repeated Measures with two levels was conducted in $\mathrm{G}^{*}$ Power to determine enough sample size using an alpha of 0.05 , a power of 0.80 , and a medium effect size $(f=0.40)$. Independent t-test was used to compare the post-treatment values of the two groups, and Paired t-test for comparison between two groups. Least Significant Difference test was used to compare within group (prevs post-treatment) differences. Results are expressed as mean \pm standard deviation or median, minimum and maximum. $\mathrm{P}$ value $\leq 0.05$ was considered significant.

Table (1): Test of normality, Kolmogorov-Smirnov test.

\begin{tabular}{|l|c|c|c|c|c|c|}
\hline \multirow{2}{*}{} & \multicolumn{3}{|c|}{ Kolmogorov-Smirnov $^{\mathbf{a}}$} & \multicolumn{3}{c|}{ Shapiro-Wilk $^{\text {Sif }}$} \\
\cline { 2 - 7 } & Statistic & $\mathbf{d f}$ & Sig. & Statistic & df & Sig. \\
\hline CRP Pre & .092 & 30 & $.200^{*}$ & .971 & 30 & .557 \\
\hline LDH Pre & .096 & 30 & $.200^{*}$ & .960 & 30 & .313 \\
\hline LDH Post & .116 & 30 & $.200^{*}$ & .960 & 30 & .302 \\
\hline Total WBCs Pre & .121 & 30 & $.200^{*}$ & .964 & 30 & .394 \\
\hline Total WBCs Post & .187 & 30 & .099 & .905 & 30 & .061 \\
\hline Absolute Neutrophils Pre & .151 & 30 & .080 & .945 & 30 & .123 \\
\hline Absolute Neutrophils Post & .173 & 30 & .083 & .875 & 30 & .082 \\
\hline Chest Expansion Pre & .113 & 30 & $.200^{*}$ & .971 & 30 & .561 \\
Chest Expansion Post & .128 & 30 & .097 & .940 & 30 & .063 \\
\hline
\end{tabular}

*. This is a lower bound of the true significance.

\section{a. Lilliefors Significance Correction}

From the above table, the normality test showed that the population is normally distributed since the significance values for all the variables are $>0.05$. This means that the data is suitable for applying parametric tests. The following are the t-tests test results for the variables. Other ordinal variables will be done using non parametric tests. 


\section{RESULTS}

There was a statistically insignificant difference between both control and study groups regarding the age, sex, weight and height of the subjects where P-values were (p-values are all >0.05) (Table 2).

Table (2): Demographic data of patients in both groups

\begin{tabular}{|c|c|c|c|c|}
\hline & Group A $(n=15)$ & Group B $(n=15)$ & Test Statistic & P value \\
\hline \multicolumn{3}{|c|}{ Gender } & \multirow{3}{*}{$\begin{array}{c}\text { Chi-Square = } \\
2.177\end{array}$} & \multirow[t]{3}{*}{0.117 (NS) } \\
\hline boys & 8 & 5 & & \\
\hline girls & 7 & 10 & & \\
\hline $\begin{array}{l}\text { Age (years) } \\
\text { Weight (kg) } \\
\text { Height }(\mathrm{cm})\end{array}$ & $\begin{array}{c}8.9 \pm 2.28 \\
30.8 \pm 9.5 \\
134.39 \pm 13.9\end{array}$ & $\begin{array}{c}9.13 \pm 1.76 \\
31.27 \pm 6.7 \\
138.1 \pm 10.1\end{array}$ & $\begin{array}{l}t \text {-value }=-\mathbf{0 . 2 8 6} \\
\text { t-value }=\mathbf{- 0 . 1 5 5} \\
\text { t-value }=\mathbf{- 0 . 8 5 6}\end{array}$ & $\begin{array}{l}0.790 \text { (NS) } \\
0.878 \text { (NS) } \\
0.399 \text { (NS) }\end{array}$ \\
\hline
\end{tabular}

Data are expressed as mean \pm SD. $\mathbf{N S}=$ not significant $=\mathbf{p}>\mathbf{0 . 0 5}$ Post-treatment values showed a statistically, there was no statistical insignificant difference of all measurements in group B when compared with their corresponding values in group A (with $p>0.05$ ) except for the CRP and Chest Expansion where there is a significant difference between the groups with $p<0.05$. (Table 3,4 ).

Table (3): Comparison between mean values of the selected measures by group in the measured at pretreatment, and post-treatment.

\begin{tabular}{|c|c|c|c|c|}
\hline \multirow{2}{*}{$\begin{array}{c}\text { Measurements } \\
\text { Group }\end{array}$} & \multicolumn{2}{|c|}{ Mean \pm SD } & \multirow{2}{*}{$\begin{array}{c}\text { Independent } \\
\text { T-test }\end{array}$} & \multirow{2}{*}{ P-value } \\
\hline & Control Group & Study Group & & \\
\hline \multicolumn{5}{|c|}{ Inflammatory Marker - CRP (mg/L) } \\
\hline Pre-treatment & $30.19 \pm 3.021$ & $36.620 \pm 3.02$ & 1.171 & $0.143(\mathrm{NS})$ \\
\hline Post-treatment & $15.413 \pm 2.07$ & $8 \pm 2.07$ & $3.676 *$ & $0.017(\mathrm{~S})$ \\
\hline \multicolumn{5}{|c|}{ LDH Serum (U/L) } \\
\hline Pre-treatment & $331.867 \pm 28.86$ & $367.440 \pm 28.863$ & 1.125 & 0.127 (NS) \\
\hline Post-treatment & $269.22 \pm 16.428$ & $233.247 \pm 16.428$ & 2.225 & 0.058 (NS) \\
\hline \multicolumn{5}{|c|}{ Inflammatory Marker - Total WBCs (mcL) } \\
\hline Pre-treatment & $10.247 \pm 1.18$ & $11.28 \pm 1.18$ & 1.151 & 0.542 (NS) \\
\hline Post-treatment & $7.4 \pm 0.532$ & $7.053 \pm 0.532$ & 1.191 & 0.648 (NS) \\
\hline \multicolumn{5}{|c|}{ Absolute Neutrophils (cells/mcL) } \\
\hline Pre-treatment & $6.43 \pm 0.97$ & $7.127 \pm 0.97$ & 2.107 & $0.571(\mathrm{NS})$ \\
\hline Post-treatment & $4.107 \pm 0.426$ & $3.793 \pm 0.426$ & 1.904 & 0.607 (NS) \\
\hline
\end{tabular}

Data are expressed as mean $\pm \mathrm{SD}, \mathrm{S}=\mathrm{P}<0.05=$ significant, $\mathrm{NS}=\mathrm{p}>0.05=$ not significant .

Table (4): Comparison between mean values of the selected measures by group in the measured at pretreatment, and post-treatment.

\begin{tabular}{|c|c|c|c|c|}
\hline \multirow{2}{*}{ Measurements } & \multicolumn{2}{|c|}{ Mean \pm SD } & $\begin{array}{c}\text { Independent } \\
\text { T-test }\end{array}$ & P-value \\
\hline Chest Expansion & Control Group & Study Group & & \\
\hline Pre-treatment & $1.860 \pm 0.131$ & $\mathbf{1 . 9 6 0 \pm 0 . 1 3 1}$ & 1.11 & $\mathbf{0 . 5 9 5 ( N S )}$ \\
\hline Post-treatment & $\mathbf{2 . 6 1 3 \pm 0 . 1 5 3}$ & $\mathbf{3 . 4 6 0} \pm \mathbf{0 . 1 5 3}$ & $\mathbf{3 . 7 9}$ & $\mathbf{0 . 0 0 1 ( s )}$ \\
\hline
\end{tabular}




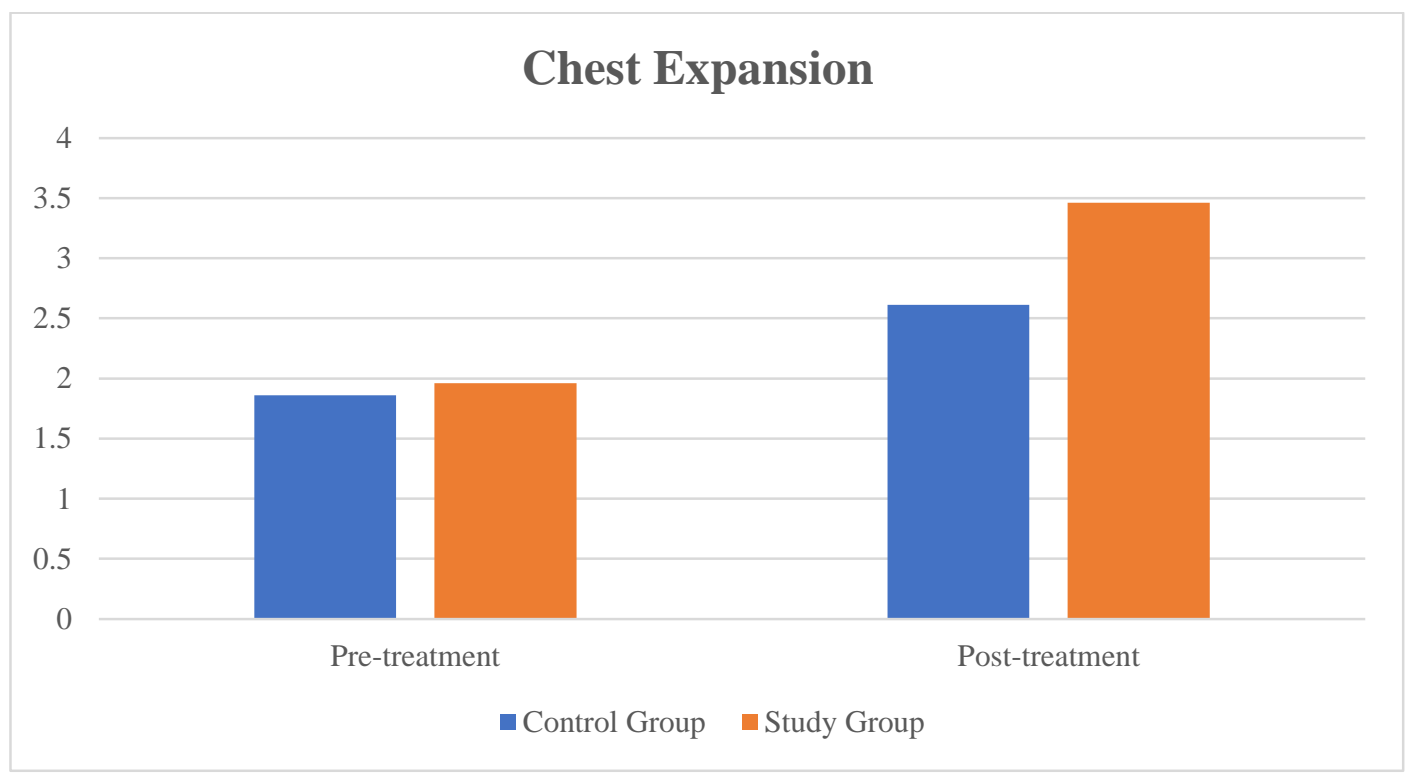

Fig. (2): Chest Expansion comparison between pre- and post-treatment for all groups

\section{DISCUSSION}

In current study, improve CRP may be due to Intermittent Pneumatic compression that may be agree with Hodge and Downey (13) who reported that compression of IPC activate lymphatic system and enhance immune cells from lymph nodes that help to decrease concentration of inflammatory mediators.

significant improvements between control and study groups regarding CRP and chest expansion in favour to study group, may be attributed to effect of application of Lymphatic pump technique that may helped in controlling the inflammation and reducing the inflammatory markers These results agreed with Creasy et al. ${ }^{(14)}$, who reported that, Lymphatic pump technique protect against pneumonia by inhibiting bacterial growth in the lung and reduce morbidity, mortality and frequency of hospitalization.

The results of the current study agree with Noll et al. ${ }^{(15)}$, who reported that Lymphatic pump decreases length of hospitalization, duration of intravenous antibiotics, and the incidence of respiratory failure.

In the current study, there was no statistically significant differences in WBCs count, absolute neutrophils and LDH between control and study groups that may be agree with Creasy $\boldsymbol{e t} \boldsymbol{a l} .{ }^{(\mathbf{1 4})}$, who reported that Lymphatic pump technique enhances the clearance of bacteria and not detect leukocytes enhancement.

There was a statistically significant difference in of WBCS and neutrophils in both groups, that may be due to conventional chest physiotherapy according to Abd el baset and Elnegamy ${ }^{(16)}$, who concluded that Chest physiotherapy in paediatric population hospitalized with pneumonia is showing improvement in respiratory rate, arterial oxygen saturation and short the time to clinical resolution.

The results of the current study agree with Hussien and Elsamman ${ }^{(17)}$ who concluded that Chest physiotherapy is effective in improving chest airways in infants with pneumonia by decreasing frequency of suction, oxygen requirement and clearance chest airways.

The results of the current study disagree with Paludo et al. ${ }^{(18)}$, who concluded that Chest physical therapy as an adjunct to standard treatment does not hasten clinical resolution of children hospitalised with acute pneumonia and may prolong duration of coughing.

\section{CONCLUSION}

It could be concluded that intermittent Pneumatic compression is recommended in treatment of community acquired pneumonia in children.

\section{REFERENCES}

1. Tattersfield A, McLuckie A (2009): Respiratory disease and its management. New York: Springer. Pp. 51 .

https://www.springer.com/gp/book/9783540162094

2. Richard E (2009): Acute and Critical Care Medicine at a Glance (2nd ed.): Wiley-Blackwell. ISBN 1-40516139-6. Retrieved 2011-04-21. https://www.wiley.com/enus/Acute+and+Critical+Care+Medicine+at+a+Glance $\% 2 \mathrm{C}+2$ nd+Edition-p-9781444327229

3. Ruuskanen O, Lahti E, Jennings L et al. (2011): Viral pneumonia. Lancet .377 (9773):1264-75

4. Wojsyk-Banaszak I, Bręborowicz A (2013): Pneumonia in Children, Respiratory Disease and Infection - A New Insight, Bassam H. Mahboub, Intech Open. https://www.intechopen.com/chapters/42153

5. Póvoa P (2002): C-reactive protein: a valuable marker of sepsis. Intensive Care Medicine, 28: 235-243.

6. Tatar D, Senol G, Anar C et al. (2013): Markers of lower respiratory tract infections in emergency departments. Multidisciplinary Respiratory Medicine, 8(1): 1-6.

7. Rubin E, Scantlen G, Chapman G et al. (1989): Effect of chest wall oscillation on mucus clearance: 
comparison of two vibrators. Pediatl Pulmonol., 6:122126.

8. Seffinger $M$, King $H$, Ward $R$ et al. (2003): Osteopathic philosophy. Foundations for Osteopathic Medicine, 2: 3-18.

9. Huff J, Schander A, Downey H et al. (2010): Lymphatic pump treatment enhances the lymphatic release of lymphocytes. Lymphat Res Biol., 8:183-7.

10. Wallace E, McPartland J, Jones J et al. (2003): Lymphatic system: lymphatic manipulative techniques. In: Ward RC, editor. Foundations for osteopathic medicine. 2nd ed Lippincott William \& Wilkins; Philadelphia: Pp. 1056-77.

11. Kumar N, Chauhan A, Patra A et al. (2018): To compare the "efficacy of pneumatic compression therapy (PCT), lymphatic drainage exercises (LDE) and control group in patient with upper limb lymphoedema. International Journal of Orthopaedics, 4(4): 658-667.

12. Zaleska M, Olszewski W, Durlik M (2014): The effectiveness of intermittent pneumatic compression in long-term therapy of lymphedema of lower limbs. Lymphatic Research and Biology, 12(2): 103109.
13. Hodge L, Downey H (2011): Lymphatic pump treatment enhances the lymphatic and immune systems. Exp Biol Med (Maywood), 236(10):1109-15.

14. Creasy C, Schander A, Orlowski A et al. (2013): Thoracic and abdominal lymphatic pump techniques inhibit the growth of S. pneumoniae bacteria in the lungs of rats. Lymphatic Research and Biology, 11(3): 183-186.

15. Noll D, Degenhardt B, Morley $T$ et al. (2010): Efficacy of osteopathic manipulation as an adjunctive treatment for hospitalized patients with pneumonia: a randomized controlled trial. Osteopathic Medicine and Primary Care, 4(1): 1-13.

16. Abd el baset W, Elnegamy $\mathbf{T}$ (2015): Effect of chest physical therapy on pediatrics hospitalized with pneumonia. International Journal of Health and Rehabilitation Sciences, 15: 209-226.

17. Hussien H, El Samman G (2011): Effect of chest physiotherapy on improving chest airways among infants with pneumonia. Journal of American Science, 7: 460-466

18. Paludo C, Zhang L, Lincho C et al. (2008): Chest physical therapy for children hospitalised with acute pneumonia: a randomised controlled trial. Thorax, 63(9): 791-794. 